\title{
ASSESSMENT OF RIDDEN HORSE BEHAVIOR
}

Carol Hall ${ }^{\mathrm{a} *}$, Nia Huws ${ }^{\mathrm{a}}$, Cassie White ${ }^{\mathrm{a}}$, Elizabeth Taylor ${ }^{\mathrm{a}}$, Heather Owen ${ }^{\mathrm{a}}$, Paul McGreevy ${ }^{\mathrm{b}}$

${ }^{a}$ School of Animal, Rural and Environmental Sciences

Nottingham Trent University

Brackenhurst Campus

Southwell

Nottinghamshire

NG25 OQF. UK.

${ }^{\mathrm{b}}$ Faculty of Veterinary Science

University of Sydney

NSW 2006, Australia

*Corresponding author: $\quad$ Carol Hall (carol.hall@ntu.ac.uk)

Telephone: $+44(0) 163681701$

\section{Abstract}

Assessments of the behavior of ridden horses form the basis of performance evaluation. The purpose of any performance being evaluated will determine the factors considered important, those indicative of 'poor' performance and what makes a successful equine athlete. Currently there is no consistent objective means of assessing ridden horse behavior and inevitably, given the different equestrian disciplines, the likelihood of a universal standard of good and bad performance is remote. Nevertheless, in order to protect the welfare of the ridden horse regardless of its specific role, we should strive for consensus on an objective means of identifying behavioral signs indicative of mental state. Current technological developments enable objective evaluation of movement patterns, but many aspects of the assessment of ridden behavior still rely on subjective judgement. The development of a list of behaviors exhibited by ridden horses, a ridden horse ethogram, will facilitate recording of observable behavioral events. However, without objective evidence of the relevance of these behavioral events, such a resource has limited value. The aim of this review is to investigate potential sources of such evidence and relate these to the assessment of ridden horse behavior. The current and potential contribution that further objective measures can make in this process is evaluated. We believe that the only way to improve the welfare of the ridden horse is by objectively identifying behavioral signs that indicate that the horse is either comfortable or uncomfortable with the activity in which it is participating. Once there is clear evidence to support this, appropriate adaptation of performance criteria in all disciplines can proceed along with alignment in training systems that ensures a mutually positive experience for both horse and human partners.

Key words: horse; equitation; ridden behavior; equestrian 


\section{Introduction}

In recent years, the welfare of horses participating in equestrian sport has become a contentious issue. Media attention and public awareness have resulted in increased pressure on governing bodies and their officials to ensure that competitive performance is not achieved the expense of horse welfare. Techniques during warm-up that would attract penalties in the competition itself are particularly topical. An evidence-based approach to warm-up techniques will help to ensure that only ethical practices prevail. To some extent the mental state of the horse will be reflected in its performance and thus can be indirectly assessed in terms of competitive success. However, there is also an onus on riders, trainers, judges and stewards to recognize signs of mental distress in the horse and respond to these signs appropriately.

This paper summarizes and reviews the literature relating to the assessment of ridden horse behavior. Assessment of both physical and psychological factors will be discussed, with a particular focus on identifying behaviors that relate to either positive or negative experiences. The compilation of a list of such behaviors is the first step towards developing a consistent descriptive tool that can be used to record the behavior of ridden horses, a ridden horse ethogram. By basing this list on behavior that is known to reflect specific mental states, such a tool will be invaluable as a means of assessing the psychological response of the horse to different ridden scenarios. This evidence-based ethogram can be used to assess the effects on horse welfare of various training methods and stimuli from competitive contexts. Appropriate adaptation of performance criteria in the light of such evidence can then be considered.

\section{Background}

The performance of ridden horses in competitive sports is currently assessed according to specific aspects of behavior and/or the consequences of that behavior (McGreevy and McLean, 2010). In certain disciplines, such as dressage and western reining, performance is judged on the quality of movement and manner in which the horse responds to signals from the rider. This is generally referred to as the 'way of going' in dressage (Fédération Equestre Internationale, 2009a) and 'quality of manoeuvres' in western reining (NRHA, 2011). In other disciplines such as show jumping, performance is judged on the objective consequences of the horse and rider's actions, usually related to speed or accuracy. Currently there is no universal or absolute measure of performance within the equestrian world and, as each discipline tests different skills, this disparity is likely to remain. However, it could be argued that there are basic requirements that underpin all equestrian performance and that, to protect the welfare of the ridden horse, a consensus should be reached regarding the behavioral events that signify negative and positive experiences for the horse. In the UK, the revision of the Animal Welfare Act (AWA) means that such an assessment has become a requirement. Under the section on 'Prevention of harm' a person has committed an offence if an act of his causes an animal to suffer (Section 4.1.a) and the suffering is unnecessary (Section 4.1.d). The Farm Animal Welfare Council's 'Five Freedoms' (Farm Animal Welfare Council, 1993) have now been included as 'needs' in the AWA that should be met by the person responsible for the animal. These needs include 'its need to exhibit normal behavior patterns' and its 'need to be protected from pain, suffering, injury and disease' (Animal Welfare Act, 2006). In order to 
conform to the requirements of this act with respect to riding horses, and to ensure that ridden horses are protected from unnecessary suffering, clear guidelines on what aspects of riding and training may adversely affect the horse are required. To date, the focus has been on identifying signs of negative mental state in ridden horses, including signs of pain and discomfort in relation to training style and equipment (for example, Cook and Mills, 2009), debate on the development of learned helplessness in the horse (Hall et al., 2008) and the negative consequences of inconsistent and inappropriate training methods (for example, Visser et al., 2009; von Borstel et al., 2009). However, objective evidence to substantiate claims that specific behavioral events are indeed the consequence of negative experiences is often lacking and differentiation between fear, pain and other sources of distress may not be clear.

It has been noted that improvements in animal welfare not only require the absence of negative experiences but should also include the promotion of positive experiences (Boissy et al., 2007). This approach has been adopted by the Fédération Equestre Internationale (FEI) in response to the debate about the impact of certain training techniques on the welfare of ridden horses. The FEI define the object of dressage as 'the development of the horse into a happy athlete as a result of harmonious education' (FEl, 2009a). However, although the FEl lists overall qualities of movement and response to the rider's signals, it does not identify more specific behavioral events indicative of the notional happy equine athlete. Whether it will be possible to demonstrate happiness on the part of the horse in any situation, let alone whilst being ridden, is debatable. At the very least, in order to improve the welfare of the ridden horse, we need to identify the behavioral signs that indicate that the horse is comfortable within its ridden work (cue equitation science). As it is in relation to dressage that the importance of positive mental state has been clearly identified, it is with reference to this equestrian sport that we start our discussion of how we can identify the happy equine athlete.

\section{Assessment of performance in dressage}

In its description of the features of the happy equine athlete, the FEI notes that through harmonious education the horse should be calm, supple, loose and flexible, but also confident, attentive and keen, thus achieving perfect understanding with the human athlete (rider) (FEI, 2009a). The overt behavior that is deemed to be indicative of this 'happy' state relates to features of the horse's way of going (freedom and regularity of the paces; harmony, lightness and ease of the movements; lightness of the forehand and engagement of the hindquarters, originating from a lively impulsion; the acceptance of the bit, with submissiveness/throughness without any tension or resistance). The premise is that overt behavior is indicative of mental state. In particular, submission relates to the effect of the horse's mental state on its physical performance. Lack of submission, as evidenced by behaviors such as tail swishing and teeth grinding, is penalized both in the marks for the movement in which it occurs and in the overall collective marks. Further descriptors of the horse's way of going are included in the training scale of the German National Equestrian Federation and these include rhythm, suppleness, contact, impulsion, straightness and collection (German National Equestrian Federation, 1997). It is with reference to these parameters that dressage performance is judged using a scoring system that ranges from 0 (not executed, with 1 being 'very bad') to 10 (excellent). 
The increasingly popular 'age' classes for potential competition horses all stipulate that successful horses must have a 'good attitude' / temperament thus acknowledging the importance of the horse's mental state. For example, the FEI judging guidelines for 5 and 6 year old potential international dressage horse classes includes temperament (attentiveness, willingness to work, natural forward going attitude, mental suppleness) as one of the features to consider when assessing the horse for potential and suitability as a dressage horse (FEl, 2009b). However, there are no indications of how these features should be assessed. The British Equestrian Federation (BEF) futurity scheme guidelines are similarly subjective, with the exception of the assessment of horses for Endurance competitions where a low heart rate is assumed to be indicative of mental calmness (BEF, 2011).

Judges in all equestrian sports undergo rigorous training and assessment and are required to attend regular standard setting days. In their report of 2009, the Dressage Task Force state that: "Good judging starts with good education!" (FEl, 2009c). This is particularly important when judging is based on subjective measures and to lessen the impact of such features as competitor bias and the running order of competitions (Wolframm, 2010). In his presentation to the FEI Dressage Training Forum in 2009, David Stickland emphasized that universally agreed standards applied in the judging of dressage performance are necessary and that one of the main challenges is to make assessment as objective as possible (Stickland, 2009). The Dressage Task Force (FEl, 2009c) identified the importance of evaluating technical developments for application to improve the transparency of dressage judging and to bring the sport to a wider public. At this year's UK National Judges Convention it was noted that judges should be objective and judge what they see, but that mistakes can be made (Kidd, 2011). Video facilities are now used at some dressage events and video footage is assessed by a Supervisory Panel who can review previous performances and amend errors of judgement where necessary. Consistency of scoring between judges has been used to measure 'good judging'. Stachurska and Bartyzel (2011) compared the ranking of performance by different judges assessing dressage tests performed at the Olympic Games in Athens (2004) and Beijing (2008) and reported that disagreement was widespread between judges in relation to specific movements. Hawson et al. (2010a) found that the greatest disagreement between judges in the 2008 Olympic dressage competition occurred in the collective marks, in particular those awarded for submission. The implication of this being that there is greater consistency between judges when physical aspects of performance are being assessed than on elements that reflect mental state. Lack of consistency between judges is a clear indication of where further guidelines are needed to clarify the criteria on which such assessments are based. However, consistency in scoring between judges is insufficient as a measure of 'good judging' if this is not underpinned by accuracy, as indicated by objective measures (Stickland, 2009).

Increasingly, contemporary technology can facilitate objective evaluation of the horse's way of going more objectively. For example, affordable tri-axial accelerometry is being used in coaching. Early work focussed on stride characteristics linked to performance. The components of stride duration, stance and swing phases were extensively analysed (Clayton, 1994a; Clayton, 1994b), kinematic data were utilised to predict performance potential of young horses (Back et al., 1994) and stride characteristics of elite sport horses were objectively measured (Deuel and Lawrence, 1986; Deuel and Park, 1990; Clayton and Barlow, 1991). More recently, transitions between trot and halt have been investigated in dressage 
horses competing at different levels. Advanced horses demonstrated more rapid changes in their limb coordination patterns and were able to maintain suspension and diagonal dissociation in the steps prior to halt than novice horses (Tans et al., 2009). However, at least initially, identification of the stride characteristics associated with excellent performance has relied on their relationship to subjective analysis. For example, when assessing quality of movement of sport horses, efforts to correlate kinematic data with subjective scoring of judges have been made (Back et al. 1994; Holmstrom et al., 1994). Biau and Barrey (2004) analysed gait variables and judges' scores for collective marks in dressage for experienced and young novice horses. Positive correlations were found between the judges' scores (subjective measurements) and objective measurements (as determined using the gait analysis system Equimetrix). These correlations were greater in the young novice group where judgement was based primarily on gait characteristics as compared with the experienced group where scoring incorporated more subjective assessment of performance features, such as submission. This again suggests that it is easier to achieve consensus regarding physical aspects of performance than those more directly affected by the horse's mental state. Consistent scoring of certain behavioral traits has been used as a means of assessing temperament and 'personality' in horses (Morris et al., 2002).Other behavioral assessment tools such as reactivity tests (Momozawa et al., 2003) and behavioral observation (Lloyd et al., 2007) have been reported. However, behavioral signs indicative of mental well-being (happiness) in ridden horses have yet to be identified.

A number of behavioral events are identified as being 'undesirable' in the ridden horse and indicative of resistance to the rider's aids. These include head positions deemed to be evasions of the bit (avoiding contact with the rider's hands), putting out the tongue, grinding the teeth and agitation of the tail, the latter three being classed as signs of nervousness, tension or resistance in the horse (FEI, 2009a). Certain animal behaviors are subjectively assessed as indicative of underlying mental states. Where there is agreement between observers it has been suggested that such qualitative assessment can be used to evaluate an animal's overall welfare state (Wemelsfelder et al., 2001). For example, when this approach was used to assess the response of horses and ponies to an environmental challenge (an open field test), observers agreed on the relevance of duration and frequency of specific behaviors. It was concluded that the link between these qualitative and quantitative findings justify objective interpretation of horse behavioral expression (Napolitano et al., 2008). However, without further evidence of the underlying mental states of the animal such conclusions may be unfounded. As noted by Derksen and Clayton (2007), although technical advances now allow quantitative assessment of certain features of the horse's performance (as noted above), quantitative evidence of the associated mental state of the horse is currently lacking. To establish whether it is indeed possible to predict subjective experience from behavioral signs, we need to gather evidence of the relationship between behavior, physiological responses and environmental factors (such as fear-eliciting stimuli). One of the main welfare-related concerns surrounding the performance and training of ridden horses relates to whether the horse experiences pain as a result of equipment and/or the behavior of the rider or trainer. The identification of pain-related behaviors that may be exhibited by the ridden horse is therefore of prime importance. 


\section{Behavior relating to pain}

In a review of the behavioral assessment of pain in horses (and donkeys) Ashley et al. (2005) noted that research in this area has lagged behind studies in farmed livestock, where husbandry procedures that elicit pain have been extensively investigated. They list behaviors that have been associated with pain in the horse, citing findings from clinical trials, clinical observations and veterinary guidelines, in addition to other review papers. They distinguish between general indicators of pain and more specific behavioral indicators of abdominal, limb and joint, head and dental pain. All of these general and specific behavioral signs (including activity and movement patterns, posture and behavioral events) could potentially be applied to the ridden horse. For example, general lethargy has been found to be a sign of pain in a range of animal species (Morton and Griffiths, 1985). Many ridden horses, in particular in riding school situations, are described as 'lazy', but it may be that some of these 'lazy' horses are actually subject to low grade pain.

The occurrence of certain behaviors has been linked to pain originating from specific locations, for example, kicking at the abdomen in response to abdominal pain (Pritchett et al., 2003). See Figure 1 which shows a ridden horse that was diagnosed as having 'behavioral problems' but subsequently was found to be suffering from an abdominal problem. Quantitative changes in the frequency or magnitude of certain behaviors also occur in response to pain (Weary et al., 2006). Although behavioral responses to severe and acute pain are usually obvious (Rietmann et al., 2004), chronic pain often results in fewer specific behavioral signs. Behavior such as 'rigid stance and reluctance to move' may be expressed in subtle ways that we are currently overlooking. Also, behavioral signs in the ridden horse may not relate specifically to the source of the pain. For example, tooth 'grinding' or contact issues although suggestive of dental pain may, in fact, be the result of pain arising elsewhere (such as in the lumbar region or hindlegs). The identification of pain in animals is generally problematic, particularly in prey species such as the horse where masking signs of pain is an important survival strategy (Taylor et al., 2002). However, as a starting point in the search for behavioral signs of pain in the ridden horse, those behaviors that could be expressed in ridden work (to a greater or lesser extent) have been selected from Ashley et al. (2005) and are shown in Table 1. Pain-related behaviors that are generally not seen in the ridden horse, such as rolling, have not been included here but the implications of such behavioral events outside of the ridden work should not be ignored. For example, aggressive behavior towards humans was shown by Fureix et al. (2010) to be exhibited by horses that were also severely affected by vertebral problems (and presumably were experiencing pain), whereas those who were unaffected or only slightly affected did not show such tendencies. 


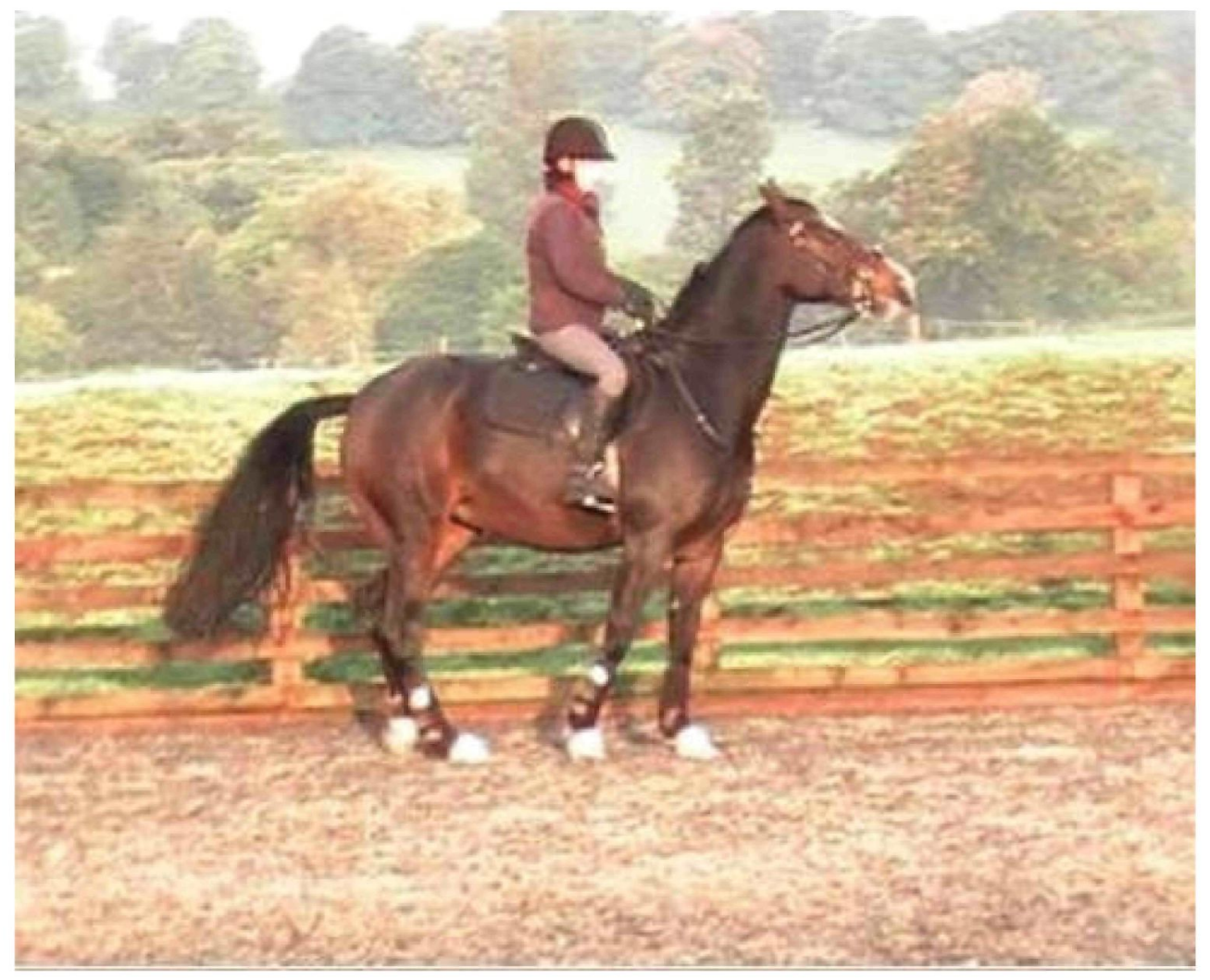

Figure 1: This horse was diagnosed as having 'behavioral problems' associated with ridden work but was subsequently found to be suffering from an abdominal complaint.

In addition to the pain-related behaviors described in Table 1, pain in the horse can be linked specifically to ridden work and is less apparent in other situations. Back pain will be exacerbated by ridden work and is often considered to be a cause of poor performance, stiffness and/or abnormality of the hind-limb gait in sport horses (Jeffcott, 1980). The withdrawal response that often occurs following palpation of the affected area may be worsened following ridden work. It has been noted that case history and clinical signs associated with vertebral column dysfunction (and associated pain) are often nonspecific and diagnosis inconclusive (Roethlisberger Holm et al., 2006). Behavior (in general as well as when ridden) exhibited by ridden horses may be indicative of pain resulting from underlying health problems (such as dental problems, limb pain) but may also be a specific consequence of the ridden work itself. When evaluating undesirable or abnormal behavior in the ridden horse (and in general) it is necessary to first rule out all possible health-related causes (McDonnell, 2005). For example, an increased understanding among riders, coaches, judges and stewards of the behavioral signs of discomfort in the ridden horse would undoubtedly enhance the welfare of many horses which, in the absence of a definitive diagnosis are labelled as 'difficult', 'naughty' or 'un-trainable'. However, when interpreting these signs it must also be noted that the behavior of the horse is affected by the skill level of the rider. Dyson (2000) noted that an unwillingness to perform does not always equate with painrelated problems, particularly when the horse is amateur-owned and produced. In contrast, a professionally produced horse may perform successfully and superficially appear sound, despite significant musculo-skeletal problems (Dyson, 2000). 
Table 1: Behavioral indicators of pain that may be expressed in the ridden horse (adapted from Ashley et al., 2005)

\begin{tabular}{|c|c|}
\hline OBSERVABLE BEHAVIOR & PAIN-RELATED ASSOCIATION \\
\hline \multicolumn{2}{|r|}{ Behavioral indicators of general pain } \\
\hline Considerable restlessness, & Characteristic of severe or acute pain. Easier to observe in confined \\
\hline $\begin{array}{l}\text { Rigid stance and reluctance } \\
\text { to move }\end{array}$ & $\begin{array}{l}\text { General indicator of pain. Horse may also appear anxious and look } \\
\text { away. }\end{array}$ \\
\hline Lowered head carriage & $\begin{array}{l}\text { Associated with depression due to chronic, severe, often unrelenting } \\
\text { pain. }\end{array}$ \\
\hline $\begin{array}{l}\text { Fixed stare, dilated nostrils, } \\
\text { clenched jaw }\end{array}$ & General facial expression of pain and fear. \\
\hline \multicolumn{2}{|r|}{ Behavioral indicators of abdominal pain } \\
\hline Vocalization (deep groaning) & Highly indicative of visceral pain. \\
\hline Kicking at abdomen & Commonly observed in response to pain source. \\
\hline Flank watching & $\begin{array}{l}\text { Frequently seen. Varies from slight head turning to intense staring or } \\
\text { actual contact. }\end{array}$ \\
\hline Stretching & $\begin{array}{l}\text { Regularly associated with colic. Limbs often placed base-wide. General } \\
\text { sign often accompanied by straining to urinate or defecate. }\end{array}$ \\
\hline Dullness and depression & Sometimes seen. \\
\hline \multicolumn{2}{|r|}{ Behavioral indicators of limb and foot pain } \\
\hline $\begin{array}{l}\text { Weight shifting between } \\
\text { limbs } \\
\text { Limb guarding }\end{array}$ & $\begin{array}{l}\text { Most commonly cited clear indicator of limb / foot pain. Shifts weight } \\
\text { from limb to limb. May be reluctant to stand on one limb. } \\
\text { Willingness to move limb could be assessed. }\end{array}$ \\
\hline Abnormal weight distribution & $\begin{array}{l}\text { Commonly observed. Pain reduction by putting less weight on affected } \\
\text { limb. Postural change varies with location of pain. Associated with } \\
\text { vertical movements of the head and neck. }\end{array}$ \\
\hline $\begin{array}{l}\text { Rotating limbs and abnormal } \\
\text { movement }\end{array}$ & $\begin{array}{l}\text { Rotated limb often indicates pain in pelvis or shoulder. High individual } \\
\text { variation. }\end{array}$ \\
\hline Reluctance to move & $\begin{array}{l}\text { Frequently cited as protective behavior indicative of major skeletal } \\
\text { damage and severe limb pain. }\end{array}$ \\
\hline \multicolumn{2}{|r|}{ Behavioral indicators of head and dental pain } \\
\hline Headshaking & $\begin{array}{l}\text { Generally suggestive of head pain. Horizontal headshaking can be } \\
\text { indicative of ear pain. Palpation of painful area (head or dental) can } \\
\text { cause head toss. Can be due to a number of different reasons and may } \\
\text { become habitual behavior, varying with season/climate. High individual } \\
\text { variation. }\end{array}$ \\
\hline $\begin{array}{l}\text { Abnormal behavior in } \\
\text { response to wearing a bit } \\
\text { and/or tilted head carriage }\end{array}$ & $\begin{array}{l}\text { Dental pain exacerbated while bitted, causes avoidance of contact and } \\
\text { aversive behavior. Tilted head carriage and/or reduction in performance } \\
\text { often the first sign of dental problems. }\end{array}$ \\
\hline
\end{tabular}


When assessing the behavior of the ridden horse we should first consider very carefully whether any unwelcome behavior exhibited could be a consequence of pain (McGreevy, 2004). This must include general signs such as lethargy and lack of responsiveness, even if this is considered the norm for that horse. Increased awareness of the full range of ridden horse behavior that is indicative of pain is the first step towards a more objective means of evaluating the subjective experience of the ridden horse. Subsequently, the development of pain scales to quantify these measures and assess the impact of training methods and equipment.

\section{Behavior relating to fear and anxiety}

Fear is induced by the perception of an actual threat or danger whereas anxiety is the emotional response induced by the perception of a potential threat or danger (Boissy, 1998). Fear of an immediate / present source of potential harm will often elicit avoidance responses in the horse which can be active (including shying, increases in speed and bolting) or passive (sudden immobility, lack of forward motion). When avoidance of the fear-eliciting stimulus is not possible the response may result in active defensive behavior (aggressive, threatening behavior). Fear is a commonly investigated emotion in the horse because such, often unexpected, reactions are a major cause of horse-human accidents (Keeling et al., 1999; Hawson et al., 2010b). In previous studies, fear eliciting situations were introduced and factors that affect the fear response assessed. Three main types of test are commonly used: the open field test (fear attributed to social isolation and a novel environment), the novel object test (fear attributed to the often sudden appearance of a novel object) and the restraint test (fear attributed to removal of flight option / inability to move / escape) (Forkman et al., 2007).

Ridden work creates social and ethological challenges akin to the fear eliciting situations described above (McGreevy and McLean 2007). The horse is often ridden alone or at least asked to move in directions independently of other horses, enter and work in novel environments, ignore novel objects within these environments (such as road signs, dustbins etc.) or approach them at speed (jumps) and accept the restraint imposed by the rider. One of the aims of training is to remove these fear responses from the behavioral repertoire of the ridden (and handled) horse. Although the active avoidance behaviors that relate to fear are relatively unmistakable (shying, bolting), behavior that occurs as a manifestation of passive avoidance (refusal to move) may not be attributed to fear but to other factors (for example, stubbornness, laziness). Additionally, the absence of these avoidance behaviors is not conclusive evidence that the horse is no longer experiencing fear but could be that it has been trained to repress these responses. This is a desirable result of training but will tend to mask behavioral evidence of the horse's mental state.

It has been demonstrated in humans and other species that facial behavior reflects affective state (Eckman and Friesen, 1969; Rosenberg, 2005) and that postures of the head and facial expressions, specific alarm calls and the release of pheromones are all indicators of fear, as is tension in the body and facial muscles (Forkman et al., 2007). Behavioral events associated with fear in horses have been recorded in a number of studies investigating factors associated with fear-eliciting situations. The results of these studies provide us with an initial indication of behavioral signs of fear in the ridden horse. Behavioral signs attributed to fear associated with restraint and handling include vocalization, ear, head, 
neck and tail position and movement (Visser et al., 2002; Visser et al., 2003). Those attributed to fear during isolation include vocalization, urination and defecation, head, neck and tail position (Le Scolan et al., 1997; Wolff et al., 1997; Seaman et al., 2002). Behavioral signs of fear attributed to novelty and startling occurrences include position and posture of head and neck, vocalization (including blowing and snorting), retraction of the eyelids, changes in ear and tail position, pawing, defecation and urination (Wolff at al., 1997; Anderson et al., 1999; Visser et al., 2001; Seaman et al., 2002).

In ridden work, the position and movement of the head and neck can be guided by the rider. When the horse fails to maintain a steady head / neck position this is often recognized and addressed. It should be noted in these circumstances that this behavior may be indicative of pain or fear of pain and potential sources of this pain considered from the outset. However, as noted by Dyson (2000) in relation to behavioral expressions of other health-related problems, such movement in ridden horses may also be affected by the behavior of the rider. In other animals additional signs of fear and discomfort are shown. For example, in cows percentage of eye white shown has been used as a measure of fear (Sandem et al., 2004) and blink rates have been associated with response to physical threat in humans (Drinkwater et al., 1968). Whether or not such signs could be indicative of mental state in the horse is as yet unclear, but further investigation is warranted (personal communication, McLean, 2010).

It is not possible to attribute a given behavior to any single emotion (Boissy, 1998). However, consistency of behavioral signs of fear across a number of different fear-eliciting situations (Visser et al., 2001) provides some evidence that these signs are indicative of fear and anxiety $n$ the ridden horse. Physiological responses to fear-eliciting stimuli, for example increased heart rate (Visser et al., 2002; Visser et al., 2003) and reduced heart rate variability, provide further evidence to support the interpretation of certain behavioral events as being fear-related. In moving animals, increases in heart rate occur as a result of physical activity and therefore this measure is limited in its application in the ridden horse. However, in a study that aimed to quantify negative mental states in ridden horses, increases in heart rate that could not be accounted for by physical activity alone were found to be associated with fear-eliciting stimuli (Jansen et al., 2009). The stimulus concerned was the sudden appearance of a novel object (opening of an umbrella) which caused an increase in heart rate. Such measures may not tell us much about the longer term affective state of horses during ridden work but do highlight the need for objective physiological measures to substantiate (or refute) current interpretations of equine behavior.

\section{Behavioral signs of mental state in the ridden horse}

As noted above, the FEI state that certain head positions are deemed to be evasions of the bit (most notably carriage of the nasal plane behind the vertical) and that putting out the tongue, grinding the teeth and agitation of the tail are classed as signs of nervousness, tension or resistance (FEI, 2009a). Behavior during ridden work has been assessed for a number of reasons, including response to different training methods (Warren-Smith and McGreevy, 2007; Innes and McBride, 2008; Visser et al., 2009; von Borstel et al., 2009), the effect of equipment (Heleski et al., 2009) and rider-related effects (Weeks, 
1996; Anderson et al., 1999; Kaiser et al., 2006; Zetterqvist Blokhuis et al., 2008). The emphasis, as has previously been the case when assessing animal welfare, has been on identifying and recording behavioral events indicative of negative mental state or distress. The commonly cited behaviors include general signs of muscle tension, vocalizations (snorting, whinnying, groaning), unusually high or low head carriage, head and neck movements (up and down, side to side, shaking, tossing, head tilt, head turning), tail position and movement (swishes, lateral or vertical movements), bucking, rearing, shying, un-cued moving backwards and at speeds and directions not asked for by the rider.

Features of equine facial expression are referred to in relation to signs of stress in ridden horses. The primary signal that is referred to is ear position and movement, both per se and as an indication of tension / relaxation. Most authors refer to the extent to which the ears are fixed in a backward-facing position (pinned back) as being a sign of negative affective state (Kaiser et al., 2006; Zetterqvist Blokhuis et al., 2008; Heleski et al., 2009; von Borstel et al., 2009), some refer to ears pointing forwards (ears pricked) as a sign of interest, alertness and attention (Innes and McBride, 2008; Heleski et al., 2009) and ears that move forward and backward independently of each other (described as listening ears by Heleski et al., 2009). To accurately interpret the underlying mental state associated with variation in ear position and movement in sheep, Boissy et al. (2011) monitored this behavior in different situations whereby the emotional context was manipulated. For example, it was shown that sheep point their ears backwards when faced with unpleasant (and uncontrollable) situations and show asymmetric ear posture when experiencing sudden/surprising situations (Boissy et al., 2011). Extreme ear positions in horses are clear signs of underlying emotion but to ensure that full and accurate interpretation of such signs are made, the methods used by Boissy et al. (2011) could be usefully applied to the horse. This may also help to explain some apparently paradoxical behavior such as the pinning back of ears just prior to the delivery of food in domestic contexts.

Position, movement and tension in the mouth and tongue are referred to when assessing ridden behavior. In the ridden context, signals are conveyed to the horse by means of pressure exerted by the rider's hands on the mouth and/or nose of the horse and behavioral responses in this area are noted. Lip licking, lip movement and mouth opening are referred to by Warren-Smith and McGreevy (2007), abnormal oral behavior by von Borstel et al. (2009) and chomping / gaping at the bit (described as more than just licking of the lips; mouth actually opens; can see air space between upper and lower jaws) by Heleski et al. (2009), as stress-related behaviors. More detailed descriptions of nose and mouth 'shapes' that relate to affective states can be found in Rees (1993), where more specific distinctions are made between long noses and tight mouths attributed to fear and anxiety; and nose wrinkling that is a attributed to 'annoyance' and 'disgust'. Such signs, as is the case with ear movement and position, require further investigation. It should also be noted that restrictive equipment such as nosebands, and the distance from which the ridden horse is often viewed (see Figure 2), will restrict both the expression and visibility of such behaviors (McGreevy et al., 2011). 


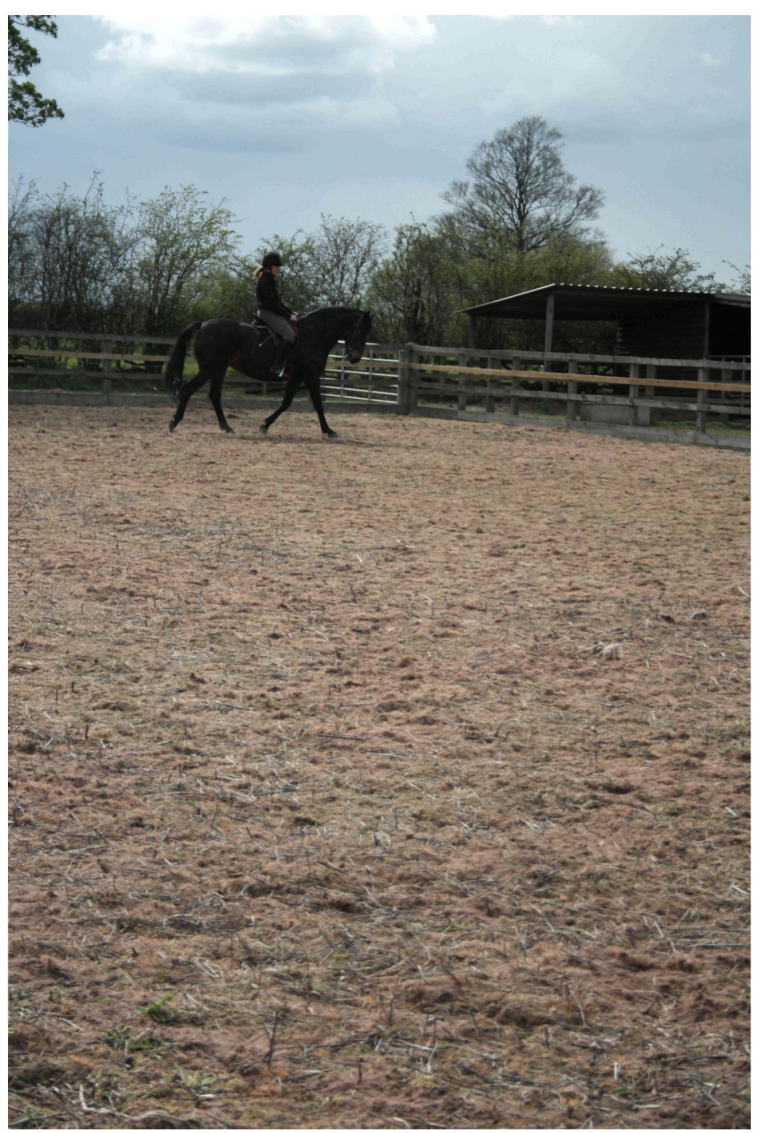

Figure 2: Ridden horse viewed from a distance of approximately 25 meters. The facial expression of this horse is not clearly visible from this distance (less than the length of a dressage arena which is 40 or 60 meters).

As noted above, the visibility of the sclera has been used to assess fear in cattle (Sandem et al., 2004) and this has been applied to assessing fear in ridden horses (von Borstel et al., 2009). This particular measure is influenced by variation in the iris of eye of the horse but other features of ocular behavior are worthy of further consideration. For example, in humans, the rate of blinking has been associated with differing levels of attention, increasing markedly at times of stress and distraction and decreasing during periods of high concentration (Gregory, 1987). This measure has not been tested yet in the horse (McLean, personal communication). Although the horse's face does not have the same mobility as that of the human, relatively minute actions may well represent an additional means of identifying mental state. Fraser (2011) suggests that relaxation of the muzzle and slight descending of the upper eyelids, together with reduced ear movement and a still tail are signs of well-being in the horse. Further evidence is required to establish whether such conclusions are warranted.

As a result of the shape of the head and lateral position of the eyes, it is only possible to fully view the face of the horse from directly in front. Even then the corners of the mouth and temporal areas of the eyes are often hidden from view. In humans it has been shown that the facial expression of emotion is not symmetrical, with more intense expressions of emotion being shown on the left side of the face (Sackeim et al., 1978). Asymmetrical exploratory behavior has been found in some horses with 
preferences shown for visually exploring emotionally provocative novel objects with the left eye (De Boyer Des Roches et al., 2008). When assessing ridden work the horse will generally be viewed from only one side at a time and lateral inequalities that may be present in equine expression will be missed.

\section{Physiological signs of mental state in the ridden horse}

By monitoring behavior in circumstances where the mental state of an animal can be predicted, accurate interpretation of behavioral signs can generally be made. However, when situations arise wherein the animal's emotional response cannot be assured, substantiation of behavioral interpretation can be made by relating events to underlying physiological states. Physiological responses to stressful situations have commonly been used to provide quantitative and objective measures that provide further evidence of an animal's mental state. Measures of sympathetic activation such as heart rate and heart rate variability and hypothalamic-pituitary-adrenal (HPA) activation (as indicated by plasma and salivary cortisol concentrations) have been used to assess the physiological response of the horse to potentially stressful situations such as transportation (for example, Smith et al., 1996; Schmidt et al., 2010a). Application of such methods in ridden horses is complicated by the reality that the response to the physical demands of exercise produces similar physiological changes to those associated with other 'stress' responses (Marlin and Nankervis, 2002). Also, drawing a distinction between increased arousal and excitement and other subjective experiences such as anxiety and fear in animals, based on such parameters is problematic. The results of current studies should be interpreted with caution but form a starting point for a more objective assessment of ridden horse behavior.

Heart rate, heart rate variability and plasma and salivary cortisol concentrations have been used extensively to assess the response of horses to potentially stressful situations, in particular those associated with mental (emotional) rather than physical stress. These measures have not been applied to the same extent to assess the mental stress of horses during ridden work and training but some important findings have been reported in the results of those studies that have used them. Schmidt et al. (2010b) recorded cortisol release, heart rate and heart rate variability during the initial training of 3year old sport horses. Their aim was to assess the potentially stressful aspects of training, including lunging and ridden work. Increases in salivary cortisol concentrations were found in response to each training step (of 2-3 ng/ml). The increase occurred 5-15 minutes after training and returned to baseline within approximately 1 hour of training. When compared with the cortisol increases reported by the same research group in relation to horses during road transport (of 4.1-6.5 ng/ml: Scmidt et al., 2010a), these increases are less, suggesting that initial ridden training is the less distressing of the two. However, the transport scenarios reported were longer in duration than the ridden work $(1,3.5$ and 8 hours road transport compared with training sessions of 20-40 minutes) and the highest concentrations of cortisol were recorded at the end of the transport sessions.

The effect of training and different western riding events on plasma cortisol concentrations was assessed by Fazio et al. (2006). Training (over 6 weeks) was found to increase baseline cortisol concentrations, until week 6 when they decreased (over training was the suggested reason for this decrease). The events that demanded speed and activity that was likely to cause excitement and anticipatory involvement of both horse and rider (barrel racing and pole bending) resulted in increases 
in plasma cortisol concentration. In reining, where calm, smooth performance is scored highly and such anticipatory involvement would be undesirable, cortisol concentration was shown to decrease. However, the former activities would presumably also be associated with greater physical demands in addition to increased excitement. In a further study Fazio et al. (2008) demonstrated an increase in plasma cortisol in Arabian horses after an 'exciting and physically demanding' gymkhana competition. The cortisol response varied according to whether the horses had previously been trained, with untrained horses showing a more rapid and greater increase in cortisol than trained horses. Whether this difference is the result of the untrained horses being less physically prepared and under greater physical stress, and/or less mentally prepared is unclear. However, in horses that are not physically challenged by an activity, increases in cortisol could be considered to be indicative of mental stress.

Heart rate at any point in time (in healthy individuals) is determined by interaction between sympathetic (increases heart rate) and vagal/parasympathetic (decreases heart rate) regulation (von Borell et al., 2007). Heart rate variability provides a measure of short-term fluctuations in beat-to-beat interval and reflects the balance between sympathetic and vagal control (Mohr et al., 2000). Physical stress is characterized by increased sympathetic tone and a decrease in vagal tone, resulting in increased heart rate and decreased heart rate variability. Mental stress and negative emotions have also been shown to result in decreased heart rate variability but the effect of physical activity on this measure must always been taken into account when interpreting the data (von Borell et al., 2007). Although increases in heart rate are primarily associated with physical activity, increases related to emotional responses have also been demonstrated to occur in the horse in response to novel/frightening situations (Visser et al., 2002). Increases in heart rate over and above those that could be accounted for by physical activity were reported by Jansen et al. (2009) to result from the appearance of a sudden novel stimulus while the horse was being lunged. An increase in heart rate was also found by Schmidt et al. (2010b) when horses were being mounted by a rider. This increase subsequently decreased as the horse began to move. Physical activity can be discounted as the cause of increases in heart rate and decreases in heart rate variability in this case (unless the horse was bracing itself against the weight of the rider mounting) and increased levels of mental stress may be implied. Novel tasks have also been shown to result in changes in heart rate despite the lack of physical activity. Horses learning a colour discrimination task were found to have higher heart rate and lowered heart rate variability during training as compared with baseline measures (Pageat et al., 2011). When horses were forced to perform a novel task (walking backwards for 3 minutes) they showed higher increases in heart rate and lower heart rate variability before they were trained in this activity, compared to when they performed the same exercise after training. The authors concluded that these measures provided a means of assessing mental stress during low intensity exercise (Rietmann et al., 2004).

In addition to the increases in heart rate that occur as a result of sympathetic activation (preparing the animal for flight or fight) certain circulatory changes occur. Associated changes in surface temperature can be measured by infrared thermography and these temperature changes have been used as a noninvasive means of assessing stress responses in animals (Stewart et al., 2005). For example, in horses subjected to a routine, but potentially stressful husbandry procedure (clipping) a significant correlation was found between increases in salivary cortisol concentration and increases in eye temperature 
(Burton et al., 2010). Subsequently infrared thermography was used to compare eye temperatures of horses lunged with or without the use of a training device (Pessoa Training Aid) and significantly higher temperatures were found with the device than without it (Hall et al., 2010). The effect of exercise on circulatory changes and the resultant skin temperature requires further investigation, but infrared thermography may provide an additional non-invasive measure of mental stress in the ridden horse.

Increases in heart rate and increases in eye temperature relate to sudden emotional (fear / flight) responses, whereas changes in cortisol concentrations reflect mental state that is of longer duration. Interpretation of these physiological measures as an indication of the mental state of the ridden horse is possible only if considered in relation to behavioral signs. Anderson et al. (1999) compared hormone concentrations (cortisol, adrenaline and nor-adrenaline) with behavioral responses in a reactivity test and temperament scores and found only tendencies for there to be a correlation between measures. In a study of the effect of lesson participation on stress levels of riding school horses, Brunt et al. (2006) found no increase in salivary cortisol concentrations, despite behavioral signs of stress (such as tail flicks). However, no details were provided regarding the sampling times of the saliva. No indication of baseline concentrations was provided either. To determine whether physiological measures provide a means of assessing the mental state of ridden horses, further evaluation is required. It is likely that by combining behavioral observation with an appropriate measure of physiological response (that is minimally affected by physical exercise) we could get closer to assessing the mental state and psychological well-being of the ridden horse.

\section{Conclusion}

It is clear that governing bodies of equestrian sport, particularly dressage, are recognising the need to increase objectivity in assessing ridden horse performance and to consider the mental state of the horse in this assessment. The latter is of prime concern, not only in terms of how this affects competitive performance, but also as a welfare issue in its own right. Accurate interpretation of behavioral signs, backed up by physiological evidence, must be the aim of those responsible for the evaluation of ridden horse performance, from whatever perspective. This information should be widely available to all involved in horse-riding, at every level. Once identified, to ensure that behavioral signs of mental state are not hidden, the use of restrictive equipment that may mask such signs should be carefully reviewed. In addition, to enable all behavioral signs that have been shown to relate to mental state to be considered, the distance and position of judges of ridden work (and stewards during warm-up) must allow them a clear view of the horse. The use of video technology should enable competitive performance to be accurately assessed and zoom footage will allow close-up consideration of signs that may otherwise be missed. The behavior of the horse in general should also be considered, with signs such as aggression and a depressed demeanour potentially relating to underlying health problems that may be causing the animal pain and result in unwanted behavior during ridden work. The first step towards ensuring that ridden horses are comfortable in their ridden work and whenever possible can indeed be described as 'happy athletes', is to objectively identify relevant behavioral signs of mental state. Subsequently, the development of a comprehensive ridden horse ethogram (that where possible attributes 'meaning' to behavioral signs) would provide an invaluable resource to allow more accurate interpretation of ridden horse behavior. The appropriate adaptation of performance criteria in all 
disciplines could then proceed along with alignment in training systems that ensures a mutually positive experience for both horse and human partners.

\section{References}

Anderson, M.K., Friend, T.H., Warren Evans, J., Bushong, D.M. 1999 Behavioral assessment of horses in therapeutic riding programs. Applied Animal Behavior Science. 63. 11-24.

Animal Welfare Act 2006. The Stationery Office Ltd. UK.

Ashley, F.H., Waterman-Pearson, A.E., Whay, H.R. 2005. Behavioral assessment of pain in horses and donkeys: application to clinical practice and future studies. Equine Veterinary Journal. 37. 565-575.

Back, W., Barnevenld, A., Bruin, G., Schamhardt, H.C., Hartman, W. 1994. Kinematic detection of superior gait quality in young trotting warmbloods. Veterinary Quarterly. 16. Supplement 2. S91-96.

Biau, S., Barrey, E. 2004. Relationship between stride characteristics and scores in dressage tests. Pferdeheilkunde. 20 (2) 140-144.

Boissy, A. 1998. Fear and fearfulness in determining behavior. In: Grandin, T. (Ed.) Genetics and the behavior of domestic animals. Academic Press. San Diego. 67-111.

Boissy, A., Aubert, A., Désiré, L., Greiveldinger, L., Delval, E., Veissier, I. 2011. Cognitive sciences to relate ear postures to emotions in sheep. Animal Welfare. 20. 47-56.

Boissy, A., Manteuffel, G., Jensen, M.B., Moe, R.O., Spruijt, B., Keeling, L.J. Winckler, C., Forkman, B., Dimitrov, I., Langbein, J., Bakken, M., Veissier, I., Aubert, A. 2007. Assessment of positive emotions in animals to improve their welfare. Physiology and Behavior. 92. 375-397.

British Equestrian Federation (2011) Futurity Guidelines, available from:

http://www.bef.co.uk/British_Breeding/BEF_Futurity.html. Accessed 23.11.2011

Brunt, A., Van Driel, K.S., Owen, D., Talling, J.C. 2006. Responses of school horses to a flat lesson. Proceedings of the $2^{\text {nd }}$ International Equitation Science Symposium. Milan, Italy. 41.

Burton, K., Hall, C., Wells, C., Billett, E. 2010. The validation of infrared thermography as a non-invasive tool to assess welfare in the horse (Equus caballus). Presented at: Recent advances in animal welfare science. UFAW Animal Welfare Conference. York. UK. 30.06.2010.

Clayton, H.M. (1994a) Comparison of the stride kinematics of the collected, working, medium and extended trot in horses. Equine Veterinary Journal. 26. 230-234.

Clayton, H.M. (1994b) Comparison of the collected, working, medium and extended canters. Equine Veterinary Journal. Supplement 17. 16-19. 
Clayton, H.M., Barlow, D.A. 1991. Stride characteristics of four Grand Prix jumping horses. Equine Exercise Physiology. 3. Available from http://www.iceep.org/pdf/iceep3/ 1130105552 001.pdf accessed 11.10 .11

Cook, W.R., Mills, D.S. 2009. Preliminary study of jointed snaffle vs. Crossunder bitless bridles: Quantified comparison of behavior in four horses. Equine Veterinary Journal. 41. 827-830.

De Boyer Des Roches, A., Richard-Yris, M-A., Henry, S. 2008. Laterality and emotions: Visual laterality in the domestic horse (Equus caballus) differs with objects' emotional value. Physiology and Behavior. 94. 487-490.

Derksen, F.J., Clayton, H.M. 2007. Is equitation science important to veterinarians? The Veterinary Journal. 174. 452-453.

Deuel, N.R., Lawrence, L.M. 1986. Gallop velocity and limb contact variables of Quarter Horses. Journal of Equine Veterinary Science. 6. 143-147.

Deuel, N.R., Park, J. 1990. The gait patterns of Olympic dressage horses. International Journal of Sports Biomechanics. 6. 198-226.

Drinkwater, B.L., Flint, M.M., Cleland, T.S. 1968. Somatic responses and performance levels during anticipatory physical-threat stress. Perceptual and Motor Skills. 27. 539-552.

Dyson, S. 2000. Lameness and poor performance in the sports horse: Dressage, Show Jumping and Horse Trials (Eventing). Proceedings of the Annual Convention of the AAEP. 46. (Reprinted in the IVIS website with the permission of the AAEP). 308-315.

Eckman, P., Friesan, W.V. 1969. The repertoire of nonverbal behavior: categories, origins, usage, and coding. Semiotica. 1. 49-98.

Farm Animal Welfare Council. 1993. Second Report on Priorities for Research and Development in Farm Animal Welfare. MAFF. Tolworth.

Fazio, E., Calabrō, G., Medica, P., Messineo, C., Ferlazzo, A. 2006. Serum cortisol levels of Quarter horses: Circadian variations and effects of training and western riding events. In: Lindner, A. (Ed.) Management of lameness causes in sport horses. Conference on Equine Sports Medicine and Science, Cambridge, UK. Wageningen Academic Publishers. 175-179.

Fazio, E., Molinari, P., Medica, P., Messineo, C., Ferlazzo, A. 2008. Circulating cortisol levels of Arab sport horses before and after gymkhana riding events: effects of training state, gender and age. In: Lindner, A. (Ed.) The acute poorly performing sport horse. Conference on Equine Sports Medicine and Science, Wageningen Academic Publishers. 165-171.

Fédération Equestre Internationale (2009a) FEI Rules for Dressage Events. $23^{\text {rd }}$ edition. Fédération Equestre Internationale. Lausanne, Switzerland. 
Fédération Equestre Internationale (2009b) Directives for International Dressage Competitions for 5 and 6 year old horses. Available from:

http://www.fei.org/sites/default/files/file/DISCIPLINES/DRESSAGE/Rules/Directives for International D ressage Competitions for 5 and 62009 2.pdf. Accessed 23.11.2011.

Fédération Equestre Internationale (2009c) Report of the FEI Dressage Task Force, available from: https://admin.fei.org/Disciplines/Dressage/News/Documents/FEl\%20DTF\%20report\%2016\%200ctober final.pdf. Accessed 23.11.2011.

Forkman, B., Boissy, A., Meunier-Salaün, M.-C., Canali, E., Jones, R.B. 2007. A critical review of fear tests used on cattle, sheep, poultry and horses. Physiology and Behavior. 92. 340-374.

Fraser, A.F. (2011) Spirit and wellness in the horse. In: Mcllwraith, C.W., Rollin, B.E .(Eds.) Equine Welfare. UFAW Animal Welfare Series. Wiley-Blackwell. Oxford. 113-129.

Fureix, C., Menguy, H., Hausberger, M. 2010. Partners with bad temper: reject or cure? A study of chronic pain and aggression in horses. PLoS ONE. 5 (8) e12434. 1-6.

German National Equestrian Federation. 1997. The Principles of Riding: The Official Instruction Handbook of the German National Equestrian Federation. Kenilworth. UK.

Gregory, R.L. (Ed.) (1987) The Oxford Companion to the Mind. Oxford University Press. Oxford.

Hall, C., Burton, K., Maycock, E., Wragg, E. 2010. A preliminary study into the use of infrared thermography as a means of assessing the horse's response to different training methods. Proceedings of the $6^{\text {th }}$ International Equitation Science Conference. Sweden. 64 .

Hall, C., Goodwin, D., Heleski, C., Randle, H., Waran, N. 2008. Is there evidence of learned helplessness in horses? Journal of Applied Animal Welfare Science. 11. 249-266.

Hawson, A., McLean, A.N., McGreevy, P.D. 2010a. Variability of scores in the 2008 Olympic dressage competition and implications for horse training and welfare. Journal of Veterinary Behavior. 5. 170176.

Hawson, L.A., McLean, A.N., McGreevy, P.D. 2010b. The roles of equine ethology and applied learning theory in horse-related human injuries. Journal of Veterinary Behavior: Clinical Applications and Research. 5. 324-338.

Heleski, C., McGreevy, P.D., Kaiser, L.J., Lavagnino, M., Tans, E., Bello, N., Clayton, H.M. 2009. Effects on behavior and rein tension on horses ridden with or without martingales and rein inserts. The Veterinary Journal. 181. 56-62.

Holmstrom, M., Fredericson, I., Drevemo, S. 1994. Biokinematic differences between riding horses judged as good and poor at the trot. Equine Veterinary Journal. Supplement 17. $51-56$. 
Innes, L., McBride, S. 2008. Negative versus positive reinforcement: An evaluation of training strategies for rehabilitated horses. Applied Animal Behavior Science. 112. 357-368.

Jansen, F., Van der Krogt, J., Van Loon, K., Avezzù, V., Guarino, M., Quanten, S,. Berckmans, D. 2009. Online detection of an emotional response of a horse during physical activity. The Veterinary Journal. 181. 38-42.

Jeffcott, L.B. 1980. Disorders of the thoracolumbar spine of the horse - a survey of 443 cases. Equine Veterinary Journal. 12. 197-210.

Kaiser, L., Heleski, C.R., Siegford, J., Smith, K.A. 2006.) Stress-related behaviors among horses used in a therapeutic riding program. JAVMA. 228. 39-45.

Keeling, L.J., Blomberg, A. Ladewig, J. 1999. Horse-riding accidents: when the human-animal relationship goes wrong! In: Proceedings of the $33^{\text {rd }}$ International Congress of the International Society of Applied Ethology, Lillehammer. 17-21 August. 86.

Kidd, J. 2011. The art of judging. British Dressage. 4. 69-71.

Le Scolan, N., Hausberger, M., Wolff, A. 1997. Stability over situations in temperament traits of horses as revealed by experimental and scoring approach. Behavioral Processes. 41. 257-266.

Lloyd, A.S., Martin, J.E., Bornett-Gauci, H.L.I., Wilkinson, R.G. 2007. Evaluation of a novel method of horse personality assessment: Rater-agreement and links to behavior. Applied Animal Behavior Science. 105. 205-222.

Marlin, D., Nankervis, K. 2002. Equine Exercise Physiology. Blackwell Science. Oxford.

McDonnell, S.M. 2005. Is it psychological, physical, or both? AAEP Proceedings. 51. In-depth: Behavior.

McGreevy, P. 2004. Equine Behavior: A Guide for Veterinarians and Equine Scientists. W.B. Saunders. London.

McGreevy, P., McLean, A. 2010. Equitation Science. Wiley-Blackwell. Oxon.

McGreevy P.D., McLean, A.N. 2007. The roles of learning theory and ethology in equitation. Journal of Veterinary Behavior: Clinical Applications and Research. 2. 108-118.

McGreevy, P., Warren-Smith, A., Guisard, Y. 2011. The effect of double bridles and jaw-clamping crank nosebands on facial cutaneous and ocular temperature in horses. Journal of Veterinary Behavior: Clinical Applications and Research. (In press).

Mohr, E., Witte, E., Voss, B. 2000. Heart rate variability as stress indicator. Arch. Tierz, Dummerstorf. 43. 171-176. 
Momozawa, Y., Ono, T., Sato, F., Kikusui, T.,Takeuchi, Y., Mori, Y. Kusunose, R. 2003. Assessment of equine temperament by a questionnaire survey to caretakers and evaluation of its reliability by simultaneous behavior test. Applied Animal Behavior Science. 84. 127-138.

Morris, P.H., Gale, A., Duffy, K. 2002. Can judges agree on the personality of horses? Personality and Individual Differences. 33. 67-81.

Morton, D.B., Griffiths, P.H.M. 1985. Guidelines on the recognition of pain, distress and discomfort in experimental animals and a hypothesis for assessment. Veterinary Record. 116. 431-443.

Napolitano, F., De Rosa, G., Braghieri, A., Grasso, Bordi, A., Wemelsfelder, F. 2008. The qualitative assessment of responsiveness to environmental challenge in horses and ponies. Applied Animal Behavior Science. 109. 342-354.

NRHA (2011) RULES FOR JUDGING available from http://nrha1.com/media/pdf/2011/handbook/rulesforjudging.pdf accessed 7.10.11

Pageat, P., Monnereta, P., Articlaux, F., Lecuelle, C.L., Mengoli, M., Cozzi, A. 2011. Evidence of stress thanks to physiological indicators during a cognitive test in horses. ACVB/AVSAB Veterinary Behavior Symposium Proceedings. St. Louis, Missouri. 15.07.2011. 35-36.

Pritchett, L.C., Ulibarri, C., Roberts, M.C., Schneider, R.K., Sellon, D.C. 2003. Identification of potential physiological and behavioral indicators of postoperative pain in horses after exploratory celiotomy for colic. Applied Animal Behavior Science. 80. 31-43.

Rees, L. 1991. The Horse's Mind. Stanley Paul. London.

Rietmann, T.R., Stauffacher, M., Bernasconi, P., Auer, J.A., Weishaupt, M.A. 2004. The association between heart rate, heart rate variability, endocrine and behavioral pain measures in horses suffering from laminitis. Journal of Veterinary Medicine. A 51. 218-225.

Rietmann, T.R., Stuart, A.E.A., Bernasconi, P., Stauffacher, M., Auer, J.A., Weishaupt, M.A. 2004. Assessment of mental stress in warmblood horses: heart rate variability in comparison to heart rate and selected behavioral parameters. Applied Animal Behavior Science. 88. 121-136.

Roethlisberger Holm, K., Wennerstrand, J. Lagerquist, U., Eksell, P., Johnston, C. 2006. Effect of local analgesia on movement of the equine back. Equine Veterinary Journal. 38. 65-69.

Rosenberg, E.L. 2005. The study of spontaneous facial expressions in psychology. In: Ekman, P., Rosenberg, E.L (Eds.) What the Face Reveals. $2^{\text {nd }}$ edition. Oxford University Press. Oxford. 3-18.

Sackeim, H.A., Gur, R.C., Saucy, M.C. 1978. Emotions are expressed more intensely on the left side of the face. Science. 202. 434-436. 
Sandem, A.I., Janczac, A.M., Braastad, B.O. 2004. A short note on effects of exposure to a novel stimulus (umbrella) on behavior and percentage of eye-white in cows. Applied Animal Behavior Science. 89. 309314.

Seaman, S.C., Davidson, H.P.B., Waran, N.K. 2002. How reliable is temperament assessment in the domestic horse (Equus caballus)? Applied Animal Behavior Science. 78. 175-191.

Schmidt, A., Mőstl, E., Wehnert, C., Aurich, J., Müller, J., Aurich, C. 2010a. Cortisol release and heart rate variability in horses during road transport. Hormones and Behavior. 57. 209-215.

Schmidt, A., Aurich, J., Mőstl, E., Müller, J., Aurich, C. 2010b. Changes in cortisol release and heart rate and heart rate variability during the initial training of 3-year-old sport horses. Hormones and Behavior. 58. 628-636.

Smith, B.L., Jones, J.H., Hornof, W.J., Miles, J.A., Longworth, K.E., Willits, N.H. 1996. Effects of road transport on indices of stress in horses. Equine Veterinary Journal. 28. 446-454.

Stachurska, A., Bartyzel, K. 2011. Judging dressage competitions in the view of improving horse performance assessment. ActaAgriculturaeScand Section A. 61. 92-102.

Stewart, M., Webster, J.R., Schaefer, A.L., Cook, N.J., Scott, S.L. 2005. Infrared thermography as a noninvasive tool to study animal welfare. Animal Welfare. 14. 319-325.

Stickland, D. 2009. Tools to Increase Objectivity in Dressage Judging, presentation to the FEl, available from: http://dressageanalytics.com/DA/FEIDTF v2.pdf. Accessed 23.11.2011.

Tans, E., Nauwelaerts, S., Clayton, H.M. 2009. Dressage training affects temporal variables in transitions between trot and halt. Comparative Exercise Physiology. 6. 89-97.

Taylor, P.M., Pascoe, P.J., Mama, K.R. 2002. Diagnosing and treating pain in the horse; where are we today? Veterinary Clinics of North America: Equine Practice. 18. 1-19.

Visser, E.K., Van Dierendonck, M., Ellis, A., Rijksen, C., Van Reenen, C.G. 2009. A comparison of sympathetic and conventional training methods on response to initial horse training. The Veterinary Journal. 181. 48-52.

Visser, E.K., van Reenen, C.G., Hopster, H., Schilder, M.B.H., Knaap, J.H., Barneveld, A., Blokhuis, H.J. 2001. Quantifying aspects of young horses' temperament: consistency of behavioral variables. Applied Animal Behavior Science. 74. 241-258.

Visser, E.K., van Reenen, C.G., Rungren, M., Zetterqvist, M., Morgan, K., Blokhuis, H.J. 2003. Responses of horses in behavioral tests correlate with temperament assessed by riders. Equine Veterinary Journal. 35. 176-183. 
Visser, E.K., van Reenen, C.G., van der Werf, j.T.N., Schilder, M.B.H., Knaap, J.H., Barneveld, A., Blokhuis, H.J. 2002. Heart rate and heart rate variability during a novel object test and a handling test in young horses. Physiology and Behavior. 76. 289-296.

Von Borell, E., Langbein, J., Després, G., Hansen, S., Leterrier, C., Marchant-Forde, J., Marchant-Forde, R., Minero, M., Mohr, E., Prunier, A., Valance, D., Veissier, I. 2007. Heart rate variability as a measure of autonomic regulation of cardiac activity for assessing stress and welfare in farm animals - A review. Physiology and Behavior. 92. 293-336.

von Borstel, U.U., Duncan, I.J.H., Shoveller, A.K., Merkies, K., Keeling, L.J., Millman, S.T. 2009. Impact of riding in a coercively obtained Rollkur posture on welfare and fear of performance horses. Applied Animal Behavior Science. 116. 228-236.

Warren-Smith, A.K., McGreevy, P.D. 2007. The use of blended positive and negative reinforcement in shaping the halt response of horses (Equus caballus). Animal Welfare. 16. 481-488.

Weary, D.M., Niel, L., Flower, F.C., Fraser, D. 2006. Identifying and preventing pain in animals. Applied Animal Behavior Science. 100. 64-76.

Weeks, J. 1996. Equine agitation behaviors. Equine Practice. 18. 23-24.

Wemelsfelder, F., Hunter, T.E.A., Mendl, T., Lawrence, A.B. 2001. Assessing the 'whole animal': a free choice profiling approach. Animal Behavior. 62. 209-220.

Wolff, A., Hausberger, M., Le Scolan, N. 1997. Experimental tests to assess emotionality in horses. Behavioral Processes. 40. 209-221.

Wolframm, I. 2010. The Psychology of Judging. Presentation at the Global Dressage Forum, Netherlands.

Zetterqvist Blokhuis, M., Aronsson, A., Hartmann, E., Van Reenen, C.G., Keeling, L. 2008. Assessing the rider's seat and horse's behavior: Difficulties and perspectives. Journal of Applied Animal Welfare Science. 11. 191-203. 